\title{
Analysis of Digital Terrain Model from LiDAR Data Using Hydro Enforcement Method on Aquatic Object in SEZ Tanjung Lesung
}

\author{
Elisya Febriana and Agung Budi Cahyono
}

\begin{abstract}
LiDAR (Light Detection and Ranging) is an active remote sensing system using a laser beam that can generate information about ground topographic characteristics in a horizontal and vertical position. In Indonesia it is still rare to use green waves in LiDAR data retrieval, so the infrared wave generates a value the point cloud elevation is refracted because it can not penetrate the depth of the water. In making aquatic objects from LiDAR acquisition results required method to create a surface water is better. One method of making DTM in aquatic area on data processing LiDAR is hydro enforcement. DTM processing using hydro enforcement method starting from draping terrain of aquatic bodies, eliminating mass points in waters up breakline formation for aquatic bodies according to draping results that have intervals between points cloud in the water body is 0.5 meters. Then do the process of macro hydro enforcement on LiDAR processing software. The results of this study indicate the quality of DTM with hydro enforcement method provides smooth and good visualization for planning infrastructure in irrigation works, water gates and providing good detail. However, this hydro enforcement method still lacks in terms of accuracy, so that the elevation of the aquatic bodies can not be used as a benchmark prior to the sampling field data retrieval.
\end{abstract}

Keywords-Digital Terrain Model, Hydro Enforcement, LiDAR.

\section{INTRODUCTION}

LiDAR is one of the technologies used in accelerating map creation basic. LiDAR is a system of Airborne Laser Scanning (ALS) [1]. In general wave which is emitted by the sensor consists of two parts, namely green waves and infrared waves. The green wave serves as a penetrating wave if a laser beam is concerned waters area. Green wave serve to measure the depth data, while the infrared wave serves to measure topographic data of land or earth surface. But, at Indonesia still rarely uses green wave, so from that X, Y, Z waters area the acquisition can not penetrate the depth of the waters and the results are refracted not according to the conditions. In making the aquatic objects of LiDAR acquisition results required method to make waters better.

In the manufacture of Digital Terrain Model (DTM) from LiDAR acquisition results, in the waters area required a special method that must be added in data processing LiDAR. One method of making LiDAR DTM is hydro enforcement.

Elisya Febriana and Agung Budi Cahyono are with Department of Geomatic Engineering, Institut Teknologi Sepuluh Nopember, Surabaya, 60111, Indonesia. E-mail: agungbc@geodesy.its.ac.id.

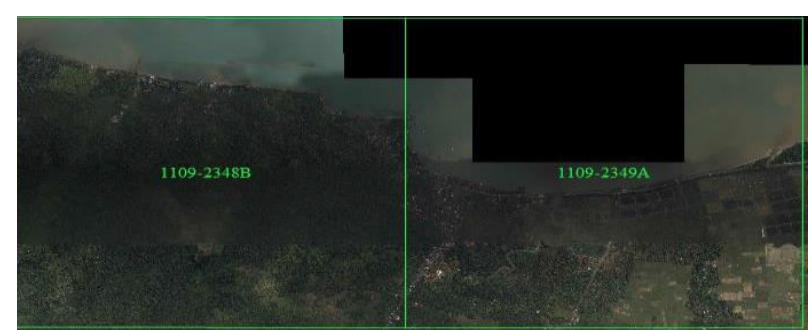

Figure 1. Research location of SEZ Tanjung Lesung MSN 1109-2348B and $1109-2349 \mathrm{~A}$

The hydro enforcement method is the concept of DTM formation where water will flow from high places to a low place. The hydrographic element (river, tributary, groove) in the DTM must flow a region to be able to describe the actual situation. In this study will be done analysis of DTM manufacture from LiDAR data using hydro enforcement method on object especially in the area of Special Economic Zone (SEZ) Tanjung Lesung, Banten. With the LiDAR acquisition has been added hydro enforcement method in SEZ Tanjung Lesung can provide visualization to describe the actual condition as reference for the development of SEZ Tanjung Lesung infrastructure. The number of water areas in SEZ Tanjung Lesung make hydro enforcement method to be one solution in the manufacture of DTM on aquatic objects.

\section{METHODOLOGY}

\section{A. Research Area}

LiDAR data in this final project is located at SEZ Tanjung Lesung, Banten Province with coordinates $6^{\circ} 31$ '27.5"S $6^{\circ} 31^{\prime} 48.7^{\prime \prime} \mathrm{S}$ and $105^{\circ} 41^{\prime} 32.0^{\prime \prime} \mathrm{E}-105^{\circ} 43^{\prime} 38.4^{\prime \prime} \mathrm{E}$ at Map Sheet Number (MSN) 1109-2348B and 1109-2349A, shown in Figure 1.

\section{B. Tools and Data Acquisition}

Data needed in this research are:

1. Data digitized aerial photos 2D SEZ Tanjung Lesung, Banten MSN 1109-2348B and 1109- 2349A in 2017

2. Air photo data SEZ Tanjung Lesung, Banten MSN 1109-2348B and 1109-2349A years 2017

3. Digital Terrain Model LiDAR Data SEZ Tanjung Lesung, Banten MSN 1109-2348B and 1109-2349A in 2017

Equipment used in this research is as follows:

1. Hardware

a. Mouse

b. Acer Aspire 4743 Laptop 
The $3^{\text {rd }}$ Geomatics International Conference 2018

TABLE 1.

SPECIFICATIONS OF ACER ASPIRE 4743 LAPTOP

\begin{tabular}{cc}
\hline \hline Specification & Information \\
\hline Prosesor Memory & Core $^{\mathrm{TM}}$ i3-380mM (2.1GHz) 6 GB DDR3 \\
(RAM) Graphics & Intel HD graphics 320GB \\
Type HDD & \\
\hline \hline
\end{tabular}

2. Software
a. Word processing software
b. Number processing software
c. LiDAR data processing software

\section{Research Method}

The processing stage is described with the following explanation:

1. Input LiDAR data

LiDAR data used already LiDAR point cloud data that has MKP (Model Key Point). The MKP on this LiDAR data is 4 ppm (point per meter) so that every 4 point cloud ground is represented by 1 point cloud ground for Lidar density 4 ppm or per 2 meters, so the size of the MKP file will be smaller than with a total point cloud ground. And 2D digitized data that has been passed through the process quality control of topology and polygon making stages stored in geodatabase (gdb) format with UTM coordinate system. And ensuring high reference system of the hipsographic dataset feature is already using EGM 2008 Geoid. Then separate the digitasi only waters area.

2. Draping elevation from point cloud

In draping the height of this point cloud becomes a reference for these waters will be flowing. And it needs to be seen elongated so as not to be wrong in point determination high.

3. Point classification in waters

Mass point is a high point on the ground surface that does not include spotheigth (high point on the top of the mountain or hill and on the basin at the ground level). No there is a mass point that is in the waters. And need to be careful of spikes. In addition to eliminating the mass point also performed the steps to eliminate spikes on LiDAR data. Spike is a high point with elevation values well above or below points around. In this point classification all point cloud in the waters are classified into low points so as not to disturb the elevation point of the elevation such waters.

\section{Breakline of water bodies}

Breakline is added in DTM that has been processed to form terrain according to field conditions. The breakline element used is the element hydrography streams of two lines and a flat-water element occupies space like a swamp and Lake.

5. Run macro hydro enforcement

Run Macro on LiDAR processing software is the final process for making DTM with Hydro enforcement method. By classifying point cloud in the waters from ground point to low point. Then enter breakline of the water body.

6. Visualization of profile path

See the direction of water flow with path profile. By looking at it elongated or can see the direction of the river flow better after using the hydro enforcement method.
July $12^{\text {th }} 2018$, Institut Teknologi Sepuluh Nopember, Surabaya, Indonesia

\section{RESULT AND DISCUSSIONS}

\section{A. LiDAR data}

The initial stage before doing LiDAR data processing using hydro enforcement method for aquatic area is to prepare LiDAR data that has been in Model Key Point (MKP). Model Key Point (MKP) is used as the initial input data for do the classification point on hydro enforcement processing. MKP is the point representative cloud ground. MKP can be made based on sampling point based on distance interval or number of points.

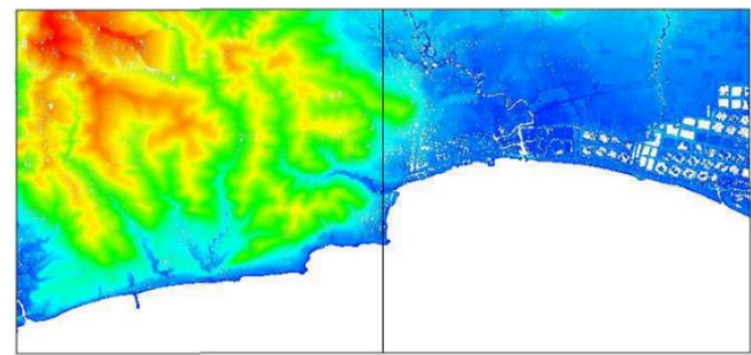

Figure 2. MSN 1109-2348B and 1109-2349A that have been in MKP and Ground Classification

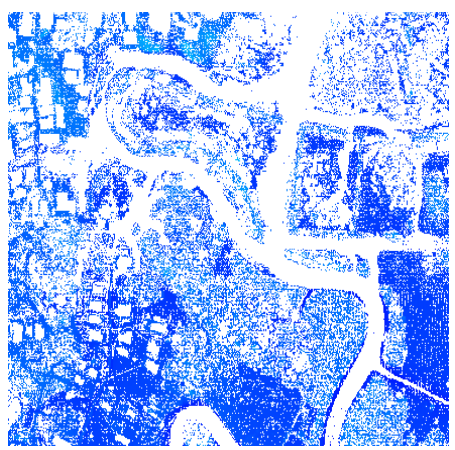

Figure 3. Example Point Cloud of Aquatic Area.

Seen from the shape of the river in the picture above, there are still many mass points in the area the waters that make the river topographic shape unlike the river that should flow from upstream to downstream.

\section{B. Drawing Terrain from Point Cloud}

Draping is an activity to know the elevation of the LiDAR cloud point as a reference to the determination of where the water's direction flows to the sea. Draping is done on terrain elevation grid point cloud LiDAR that has a height. In doing the draping necessary precision to determine the high point cloud water level. In deciding height of puddles, swamps, ponds, sea, rice field categorized waters that are not flowing, then the height is made 0 meters because no flow is considered flat. Results This draping is used as the altitude reference for breakline formation in the making water bodies. From the results of $2 \mathrm{D}$ digitization 21 big rivers, 42 small rivers and 4 regions which is considered flat (flattern).

\section{Point Classification In Aquatic Area}

LiDAR point classification from default class to low point for point cloud inside digitasi waters. For this classification use macro by classify in processing software LiDAR. 
The $3^{\text {rd }}$ Geomatics International Conference 2018

July $12^{\text {th }} 2018$, Institut Teknologi Sepuluh Nopember, Surabaya, Indonesia

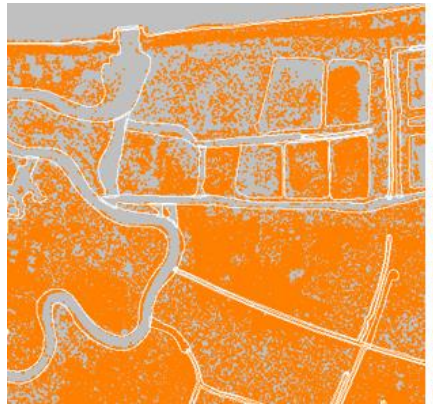

(a)

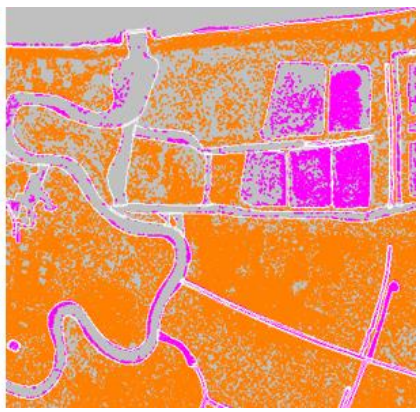

(b)
Figure 4. (a) Before the Classification of the Ground Point to Low Point, (b) After Classification from Ground Point to Low Point

From the results of the classification there are 46.972 of 3.644.766 points in MSN 1109-2348B.las and there are 232.751 of 3.009.222 points in MSN 1109-2349A.las that were successfully classified into in the low point. It has been seen from a different color, to orange ground and for the waters are classified into purple.

\section{Breakline of Bodies on Aquatic Objects}

Making the breakline follows the line of aquatic objects bodies. At this breakline stage is included the initial and final elevation values of each river at the time of draping. The elevation value determine the direction of river water flow. Having the density between the cloud point in the water is 0.5 meters.

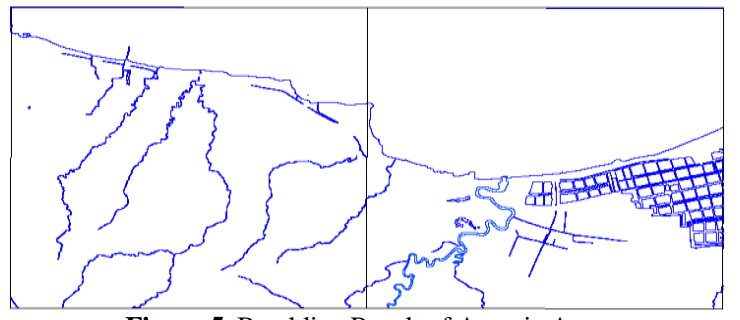

Figure 5. Breakline Result of Aquatic Area.

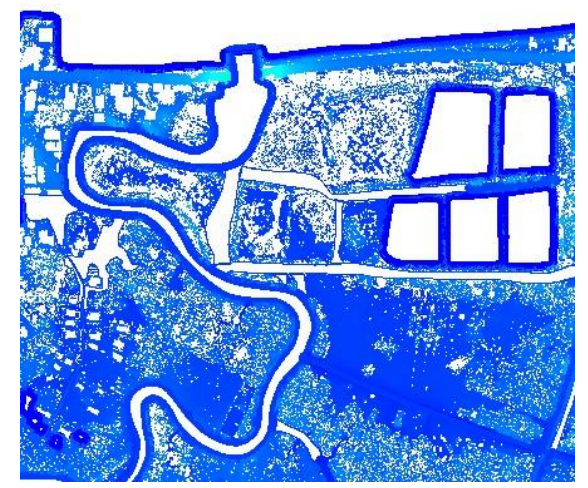

Figure 6. Example Breakline of Bodies on Aquatic Objects

\section{E. Run Macro Hydro Enforcement}

Run macro hydro enforcement is one of the stages for LiDAR data classification. With parameters specified, the macro will change the point in the inside shape of the water become a low point and add water points to breakline results that will represent the waters face can be well recognized in the formation of DTM.

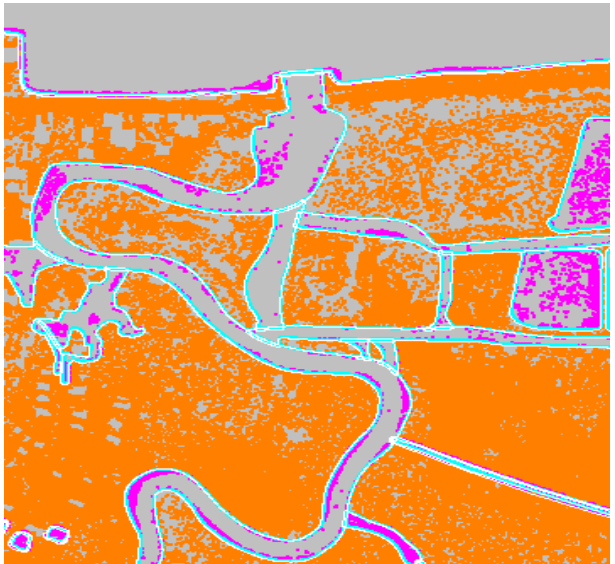

Figure 7. Run Result Macro Hydro Enforcement

There is an additional color in the image above, ie light blue signifies the water breakline (water classification) has entered with other point cloud. Then make the new output with .las format to see DTM formation after macro hydro enforcement.

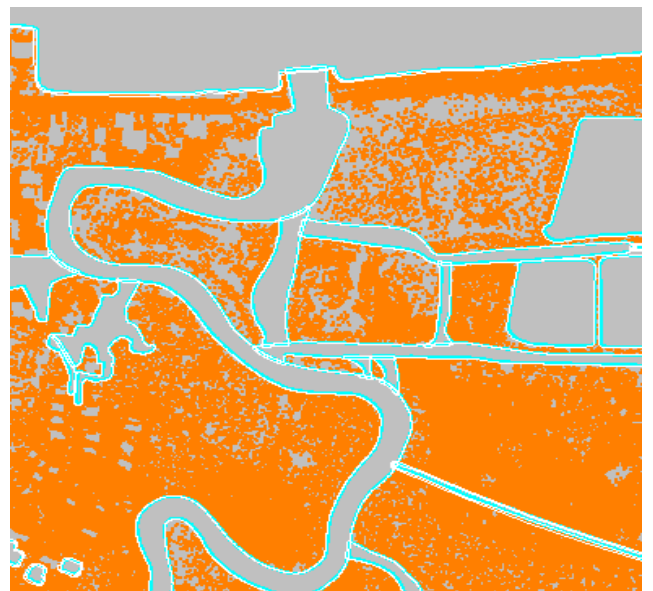

Figure 8. Run Result Macro Hydro Enforcement Already No Cloud Point Being in Water Areas

\section{F. Visualization of Profile Path}

Path profile is one tool to know the surface level of the waters already flowing or not. And can know the elevation of the surface of the waters. Previously the output from after macros had been made elevation grid by triangulation method (Grid TIN of Points). After forming a Digital Terrain Model (DTM) can only be used tool path profile to know profiling transversely or elongated in water areas.

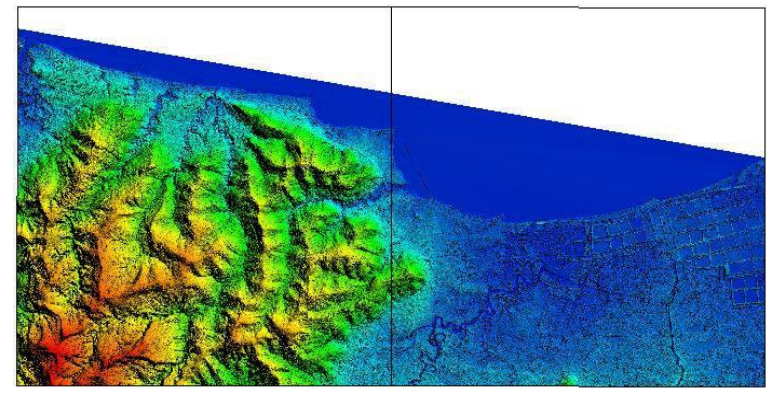

Figure 9. DTM Results Before Using Hydro Enforcement Method. 
The $3^{\text {rd }}$ Geomatics International Conference 2018

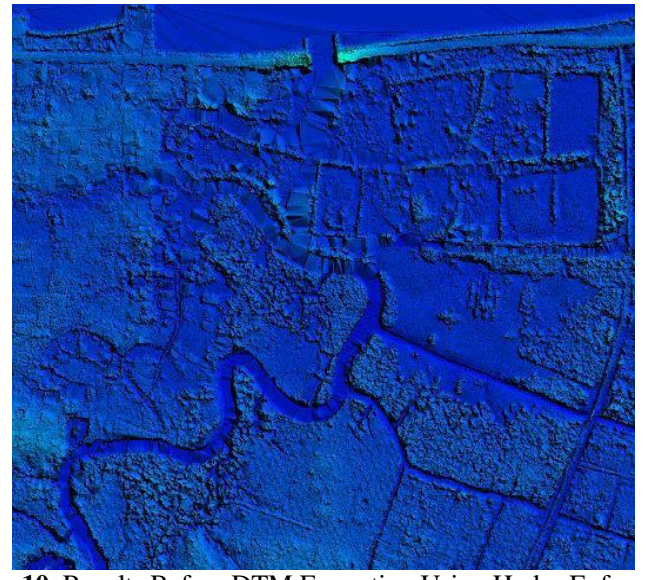

Figure 10. Results Before DTM Formation Using Hydro Enforcement Method.

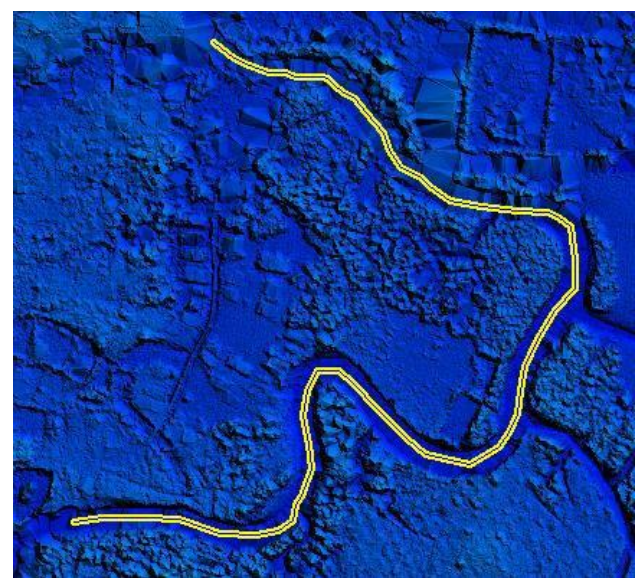

Figure 11. One River for Example Path Profile Before Using Hydro Enforcement Method.

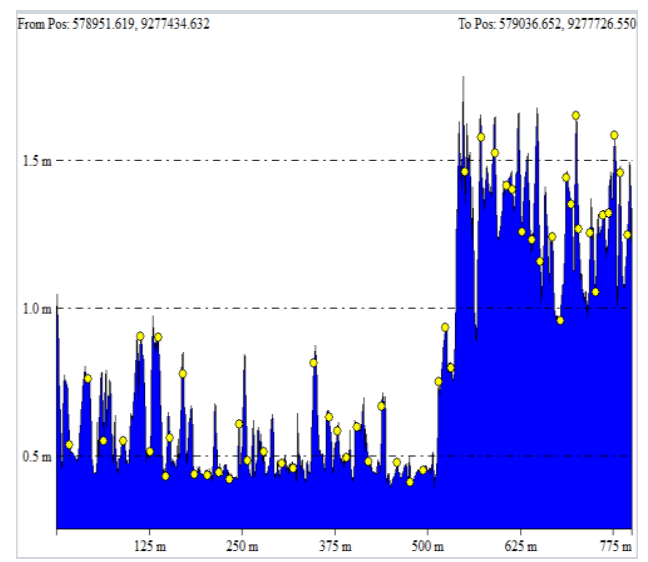

Figure 12. River Path Profile Result Before Using Hydro Enforcement Method.

From the path profile in the picture above can be concluded if the lengthwise follow the flow river before using the hydro enforcement method has a significant elevation change and so do not know where the river flow goes. High differences occur which is very different and it can be said that noise should be eliminated. As is hydro enforcement method, the river looks like the Figure 13.
July $12^{\text {th }} 2018$, Institut Teknologi Sepuluh Nopember, Surabaya, Indonesia

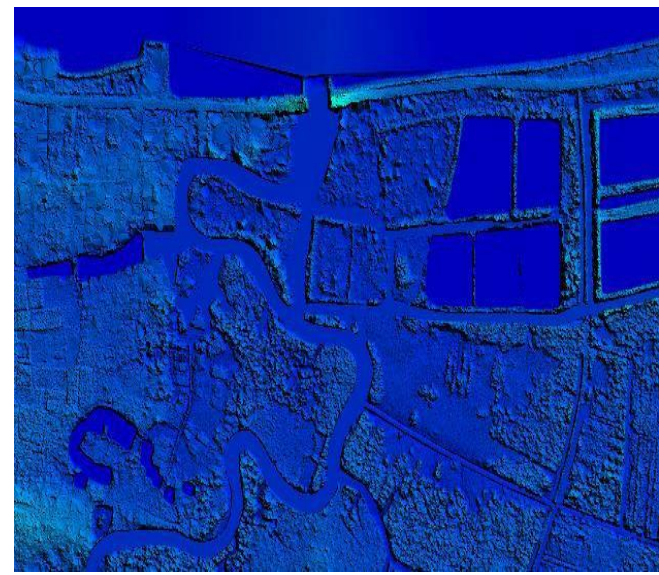

Figure 13. One River being Example Path Profile After Using Hydro Enforcement Method.

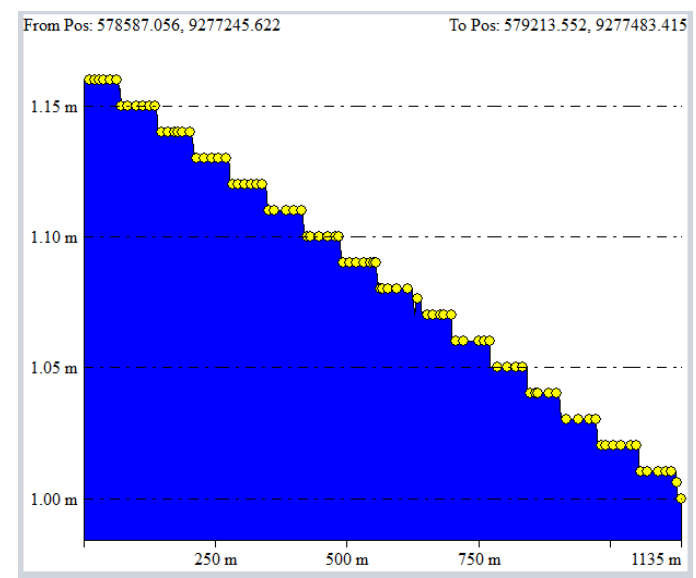

Figure 14. Result of River Path Profile After Using Hydro Enforcement Method

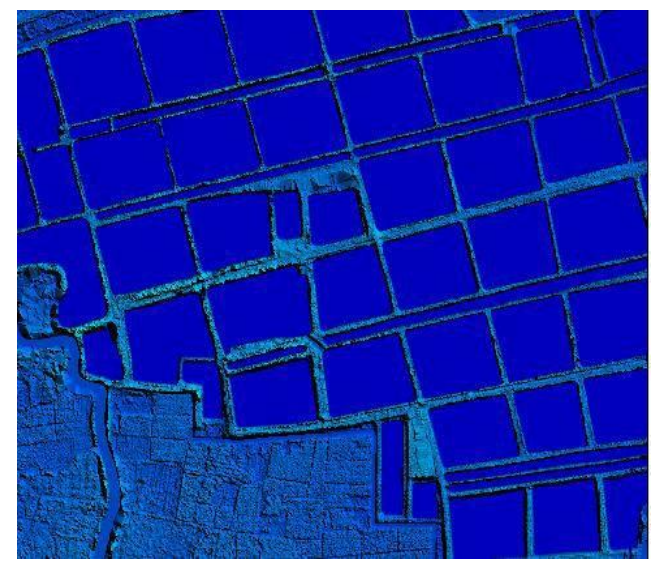

Figure 15. Example of Results of Area with 0 Meters elevation at Pond Area.

The aquatic area looks much smoother and better recognizable. The hydro enforcement method helping to perfect topography in the most approaching waters section with actual appearance.

In the path profile result after using hydro enforcement method has a decrease streams that flow constantly and know the direction of the water flow is seen from elevation. With a 
The $3^{\text {rd }}$ Geomatics International Conference 2018

July $12^{\text {th }}$ 2018, Institut Teknologi Sepuluh Nopember, Surabaya, Indonesia

difference of 0.01 meters to make the flow of the river flows smoothly. And 0 meters height applies to ponds, ponds and other areas that are inundated.

\section{G. Application Process Hydro Enforcement Method}

Starting from the process of draping, making a flattern or rub the mass point that is on waters then making breakline for aquatic bodies at the stage of manufacture DTM using hydro enforcement method can be said according to interpretation each operator is processing. And draping errors can create mismatches against the aquatic bodies looks different if it is used as DTM. Process of hydro enforcement method can only be tested according to the quality of its DTM according to the implementation instructions provided by the Geospatial Information Agency. The quantity of elevation values in river bodies is not can be an accurate reference.

\section{CONCLUSION}

Based on the analysis of DTM establishment from LiDAR using hydro enforcement method, the following conclusions are obtained:

1. Based on its quality, the advantages of DTM results with hydro enforcement method provides good visualization

based on the appropriate DTM quality tests and clear terrain detail in high resolution for local infrastructure planning SEZ Tanjung Lesung in arranging the area, constructing the irrigation and sluice, and giving good and clear detail.

2. Hydro enforcement method still has flaws in terms of accuracy, because it is tested in quality based on 10 parameters and the quantity test is done only on postprocessing LiDAR data before entering LiDAR data manual classification process.

\section{ACKNOWLEDGMENT}

The authors give thanks to thank the Geospatial Information Agency and PT. Waindo Specterra which has provided air photo data and LiDAR area of SEZ Tanjung Lesung, Banten.

\section{REFERENCES}

[1] A. Wehr and U. Lohr, "Airborne laser scanning-an introduction and overview," ISPRS J. Photogrametry Remote Sens., vol. 54, pp. 68-82, 1999. 